\title{
Laws Applicable to Medical Practice and Hospitals in India
}

\author{
${ }^{1}$ Madhav Madhusudan Singh, ${ }^{2}$ Uma Shankar Garg, ${ }^{3}$ Pankaj Arora
}

\begin{abstract}
Healthcare in India features a universal healthcare care system run by the constituent states and territories. Law is an obligation on the part of society imposed by the competent authority, and noncompliance may lead to punishment in the form of monetary fine or imprisonment or both. The earliest known code of laws called the code of Hammurabi governed the various aspects of health practices including the fees payable to physician for satisfactory services. The first ever code of medical ethics called the Hippocratic oath was laid down 2500 years ago, in the 5th century BC, by Hippocrates-the Greek physician. The modern version of Hippocratic Oath (called the declaration of Geneva), devised by the WHO after the second world war and is accepted by international medical fraternity. The process of establishment of healthcare system during the colonial rule also necessitated creation of legislative framework for practitioners of medicine. As the number of doctors qualified in Indian medical colleges increased, creation of laws for them became necessary. The medical council of India, a national level statutory body for the doctors of modern medicine, was constituted after the enactment of Indian Medical Council Act 1933. The first legal recognition and registration for the Indian systems of medicine came when the Bombay Medical Practitioner' Act was passed in 1938.

Laws governing the commissioning of hospital are the laws to ensure that the hospital facilities are created after due process of registration, the facilities created are safe for the public using them, have at least the minimum essential infrastructure for the type and volume of workload anticipated and are subject to periodic inspections to ensure compliance. There are other laws pertaining to governing to the qualification/practice and conduct of professionals, sale, storage of drugs and safe medication, management of patients, environmental safety, employment and management of manpower, medicolegal aspects and laws pertaining to safety of patients, public and staff within the hospital premises. There are laws governing professional training and research, business aspects, licences/certifications required for hospitals, etc. A hospital administrator should be aware about all these laws, regulations, policies, procedures, reports and returns and keep abreast with the latest amendments to be on the safe side of law and provide quality care to the patients.
\end{abstract}

Keywords: Healthcare, Law, Act, Code, Health practices, Medical ethics, Hippocratic, Declaration of Geneva, Medical council of India, Statutory body, Indian systems of medicine, Commissioning

\footnotetext{
${ }^{1,2}$ Medical Officer (Hospital Services), ${ }^{3}$ Assistant Professor

${ }^{1}$ Ministry of Defence, L Block, New Delhi, India

${ }^{2}$ Military Hospital, Panaji, Goa, India

${ }^{3}$ Department of Hospital Administration, Postgraduate Institute of Medical Education and Research, Chandigarh, India
}

Corresponding Author: Madhav Madhusudan Singh, 543 AFNO Enclave, Plot 11, Sector 7, Dwarka, New Delhi-110075 India, e-mail: mmsingh2011@gmail.com of hospital, Conduct of professionals, Environmental safety, Employment and management of manpower, Medicolegal aspects, Patient safety, Professional training, Research.

How to cite this article: Singh MM, Garg US, Arora P. Laws Applicable to Medical Practice and Hospitals in India. Int J Res Foundation Hosp Healthc Adm 2013;1(1):19-24.

\section{Source of support: Nil}

\section{Conflict of interest: None}

\section{INTRODUCTION}

Human culture is built upon the formulation of values that form the basis of an ethical society, honesty, integrity, respect, pursuit of excellence, civic duty, accountability and loyalty. Since the dawn of civilization, by trial or error, it has become established that a society and more so it's medical profession, a public oriented and noble profession, can survive and thrive only by observance and practice of certain rules of conduct guided by ethical, moral, legal and social values of land.

Healthcare in Indian features a universal healthcare care system run by the constituent states and territories. The constitution charges every state with 'raising the level of nutrition and the standard of living of its people and improvement of public health as among its primary duties. Law is an obligation on the part of society imposed by the competent authority, and noncompliance may lead to punishment in the form of monetary fine or imprisonment or both.

In a survey conducted at Mumbai, eight out of 10 doctors feel that the laws that govern the practice of healthcare in India are outdated and even higher majority feels that there are too many laws and licences that are required to keep their practice going. A survey among 297 doctors across specializations says that there are about 50 different laws that govern the practice of healthcare in India. The study conducted by Medscape India, a nonprofit trust of doctors, revealed that $78 \%$ of doctors feel that many of the laws that govern medical practice are outdated. Licences have to be procured by doctors running a hospital every year. ${ }^{1}$

\section{MEDICAL LAWS IN INDIA}

The earliest civilization known to us is the Indus urban culture of 3000 to 2000 BC. The renowned medical historian Henry Sigerist ${ }^{2}$ believed that public health facilities of Mohenjo Daro were superior to those of any other community of the ancient orient. Since the ancient times, certain duties and responsibilities have been cast on persons who adopt this 
sacred profession. This is exemplified by Charak's Oath (1000 BC) and Hippocratic Oath (460 BC). The written evidence of the state's involvement and regulatory function is available from the Kautilya's Arthashastra. Kautilya considered famine as a bigger calamity than pestilence and epidemics, as the remedies can be found for the diseases. He believed that the king should order the physician to use medicine to counter epidemics. ${ }^{3}$

The earliest known code of laws of health practices were the laws formulated around $2000 \mathrm{BC}$ by Hammurabi, the great king of Babylon. These laws, also called the code of Hammurabi governed the various aspects of health practices, including the fees payable to physician for satisfactory services. The laws were drastic and penalties for harmful therapy stringent. Doctors whose proposed therapy proved wrong ran the risk of being killed. This was the first codification of medical practice.

The first ever code of medical ethics called the Hippocratic oath was laid down 2500 years ago, in the 5th century BC, by Hippocrates - the Greek physician. He is remembered till today as the 'Father of western medicine'. Hippocratic oath has been guiding and regulating the conduct of doctors for centuries. The modern version of Hippocratic Oath (called the declaration of Geneva), devised by the WHO after the second world war and accepted by international medical fraternity as the international code of medical ethics, draws heavily upon the ancient oath.

During the Ashoka period (270 BC), the state showed interest in the public works and provision of medical care and as a law. He founded hospitals all over his empire with medical attendance at state expense. ${ }^{4}$ Ethics is described in the Charaka-Samhita, in details and Ayurvedic physicians of ancient India has a well-defined medical ethics". 5

The colonial power brought with them their own physicians and barber surgeons. In the mid $19^{\text {th }}$ century, as the medicine got recognized in England, it slowly started having its impact in India too. After 1857, the main factors that shaped colonial health policy in India were their concern for troops and European civil population. ${ }^{6}$

The process of establishment of healthcare system also necessitated creation of legislative framework for practitioners of medicine. In the earlier period of rule, the physicians and surgeons brought by the East India company and after 1857 by the British Government, needed some discipline and regulations. Lt Colonel DG. Crawfords 'A history of Indian medical services, 1600-1913' narrates several instances of in-discipline, insubordination, malpractice, etc. by such doctors and the punishments (including deportation) mated out to them. It also narrates the regulation devised by the East India Company for the hospitals established by them.
After the enactment of the law, establishing General Medical Council in 1857 in England, the British doctors employed in India were registered with the GMC and came under its disciplinary regulation. As the number of doctors qualified in Indian medical colleges increased, creation of laws for them became necessary.

As a part of criminal procedures and for other purposes, the colonial government had, in 1871, enacted Coroner's act applicable to Bombay and Calcutta. It defined the role of medical professionals in the work of conducting autopsy and inquests. However, the laws for the creation of indigenous medical councils took many more years for enactment. Mean-while, the laws were enacted for the the prevention of the spread of dangerous epidemic disease, for the segregation and medical treatment of pauper, etc. The epidemic disease act was first enacted in 1807 and is still in force with amendments, while the Lepers Act 1898 was repealed and substituted by another law in early 1980s.

Grant Medical College Society in 1880 passed a Bombay Medical Act and established the medical council. The draft rule of this act included the appointment of a registrar, maintenance of name in register and penalty for doing wrong things. The Bombay Presidency enacted Bombay Medical Act in 1912. Medical acts in some other provinces soon followed. The Bengal Medical Act and Madras Medical Registration Act were enacted in 1914.

These provincial acts were immediately followed by the Indian Medical Degree Act, passed by the Indian Legislative Council and approved by the Governor General in 1916.

The Medical Council of India, a national level statutory body for the doctors of modern medicine, was constituted after the enactment of Indian Medical Council Act 1933. The first legal recognition and registration for the Indian systems of medicine came when the Bombay Medical Practioner Act was passed in 1938.

\section{Post 1947 Developments}

The independence in 1947 inaugurated a new phase of development of organized health care services creating more entitlement for the people. Along with that, the state also embarked on enactment of new laws, modification of the colonial laws and judiciary developed case laws to consolidate people's entitlement of health care and to extent the rights.

At the time of independence and the first few years of planning, the task confronting the country was to create physical and institutional infrastructure for the rapid development or modernization of India.

With time, the parliament has passed a large number of bills and acts to strengthen the healthcare delivery in India. 


\section{Prerequisites of Medical Practice}

A duly qualified medical professional, i.e. a doctor has a right to seek to practice medicine, surgery and dentistry by registering himself with the medical council of the state of which he is resident, by following the procedure as prescribed under the medical act of the state.

The state medical council has the power to warn, refuse to register/remove from the name of a doctor who has been sentenced by any court for any nonbailable offence or found to be guilty of infamous conduct in any professional respect. The state medical council has also the power to re-enter the name of the doctor in the register.

The provision regarding offences and professional misconduct which may be brought before the appropriate medical council (state/medical Council of India) have been stated in the Indian Medical council (Professional conduct, etiquette and ethics) Regulation 2002. No action against a medical practitioner can be taken unless an opportunity has been given to him to be heard in person or through an advocate.

\section{Emergency Healthcare and Laws}

The supreme court has been emphatic in declaring that the fundamental right to life covered within its scope the right to emergency healthcare. The landmark judgment that marked this momentous event is that of Parmanand Katara V, Union of India (Supreme Court 1989). In this case, a scooterist severely injured in a road accident was refused for admission when taken to nearest hospital on the excuse that hospital was not competent to handle medicolegal cases. The supreme court, in its judgment, pronounced that the obligation of medical professionals to provide treatment in cases of emergencies overrode the professional freedom to refuse patients. According to the right to emergency treatment, the status of a fundamental right under Article 21 (fundamental right of life), the court categorically stated that 'Article 21 of constitution casts the obligation on the state to preserve life. Interestingly, the supreme court went on to say that not only government hospitals but also "every doctor whether at a government hospital or otherwise has the professional obligation to extend his/her service with due expertise for protecting life.

In another case (Paschim Banga Khet Majdoor Samity $v s$ State of West Bengal, Supreme Court, 1996), a person suffering from head injuries from a train accident was refused treatment at various hospital on excuse that they lacked the adequate facilities and infrastructure to provide treatment. In this case, supreme court further developed the right to emergency treatment, and went on to state that the failure on the part of government hospital to provide timely medical treatment to a person in need of such treatment results in violation of his/her right to life guaranteed under Article 21.

\section{Criminal Liability in Medical Profession}

Criminal law tries to mold the individual behavior in a socially accepted manner. It tries to enforce the rules of social mortality to a great extent. Criminal law defines certain types of human conduct as offences and prescribes the punishment for them. Remission by doctors in their duties and obligations and lapses left by them may give to criminal liabilities, the liabilities of being prosecuted in a criminal court and awarded punishment as per provision of law.

The criminal law operates on a doctor in somewhat a different manner than an ordinary persons. This is because it allows a doctor to cause injury to the patient for preventing a greater harm. The crucial area of criminal law for a doctor is offences affecting life. These offences are mainly murder, simply hurt, grievous hurt and miscarriage or abortion. A doctor may be charged for any of these offences in general. However, the criminal law arms a doctor with three formidable defences namely: (1) informed consent, (2) necessity and (3) good faith.

Various criminal liabilities in medical practice related to different sections of Indian Penal Code, the code of criminal procedure and different acts like MTP, PCPNDT, Transplantation of Human Organ Act, etc.

\section{LAWS APPLICABLE TO HOSPITALS}

\section{Laws Governing the Commissioning of Hospital}

These are the laws to ensure that the hospital facilities are created after due process of registration, the facilities created are safe for the public using them, have at least the minimum essential infrastructure for the type and volume of workload anticipated, and are subject to periodic inspections to ensure compliance. These are listed in Table 1 below:

Table 1: Laws governing the commissioning of hospital ${ }^{8}$

1. Atomic Energy Act 1962

2. Delhi Lift Rules 1942, Bombay Lift Act 1939

3. Draft Delhi Lifts and Escalators Bill 2007

4. Companies Act 1956

5. Indian Electricity Rules 1956

6. Delhi Electricity Regulatory Commission (Grant of consent for captive power plants) Regulations 2002

7. Delhi Fire Prevention and Fire Safety Act 1986, and Fire Safety Rule 1987

8. Delhi Nursing Home Registration Act 1953

9. Electricity Act 1998

10. Electricity Rules 1956

11. Indian Telegraph Act 1885

12. National Building Act 2005

13. Radiation Protection Certificate from BARC

14. Society Registration Act

15. Urban Land Act 1976

16. Indian Boilers Act 1923

17. The Clinical Establishment (Registration and Regulation) Bill 2007 


\section{Laws Governing to the Qualification/Practice and Conduct of Professionals}

These are the regulations to ensure that staff employed in the hospital for delivery of healthcare are qualified and authorised to perform certain specified technical jobs within specified limits of competence and in accordance with standard codes of conduct and ethics, their credential are verifiable from the registering councils and in case of any professional misconduct the councils can take appropriate action against them. These laws are listed in Table 2 .

Table 2: Laws governing to the qualification/practice and conduct of professionals

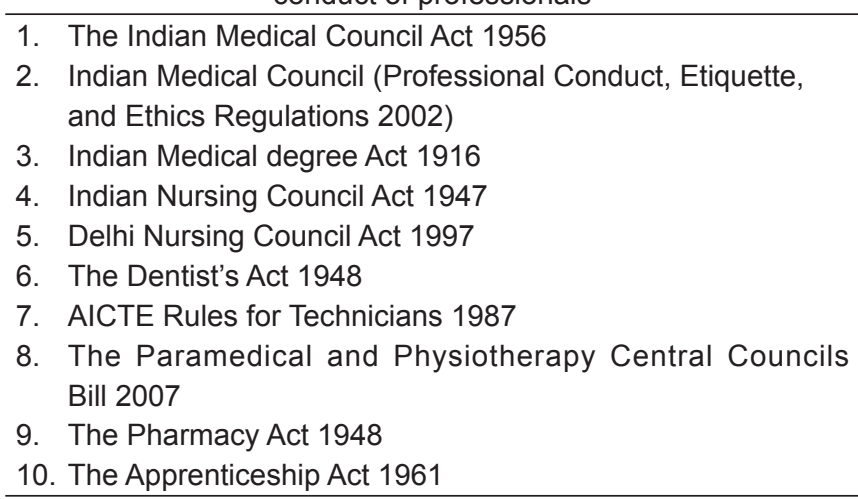

\section{Laws Governing to Sale, Storage of Drugs and Safe Medication}

These are laws to control the usage of drugs, chemicals, blood, blood products, prevent misuse of dangerous drugs, regulate the sale of drugs through licences, prevent adulteration of drugs and provide for punitive action against the offenders. These are listed in Table 3.

Table 3: Laws governing to sale, storage of drugs and safe medication

1. Blood Bank Regulation Under Drugs and Cosmetics (2nd Amendment) Rules 1999

2. Drugs and Cosmetics Act 1940 and Amendment Act 1982

3. Excise permit to store the spirit, Central Excise Act 1944

4. IPC Section 274 (Adulteration of drugs), Sec 275 (Sale of Adulterated drug), Sec 276 (Sale of drug as different drug or preparation), Sec 284 (negligent conduct with regard to poisonous substances)

5. Narcotics and Psychotropic Substances Act

6. Pharmacy Act 1948

7. Sales of Good Act 1930

8. The Drug and Cosmetics Rule 1945

9. The Drugs Control Act 1950

10. VAT Act/Central Sales Tax Act 1956

\section{Laws Governing Management of Patients}

These are the laws for setting standards and norms for conduct of medical professional practice, regulating/ prohibiting performance of certain procedure, prevention of unfair practices and control of public health problems/ epidemic disease. They deals with the management of emergencies, medicolegal cases and all aspects related there to including dying declaration, and conduct of autopsy and the types of professional negligence. These laws are listed in Table 4.

Table 4: Laws governing management of patients

1. Birth and Deaths and Marriage Registration Act 1886

2. Drugs and Magic Remedies (Objectionable) Advertisement Act

3. Guardians and Wards Act 1890

4. Indian Lunacy Act 1912

5. Law of Contract Section 13 (for consent)

6. Lepers' Act

7. PNDT Act 1994 and Preconception and Prenatal Diagnostic Tech (prohibition of sex selection) Rules 1996 (Amendment Act 2002)

8. The Epidemic Disease Act 1897

9. Transplantation of Human Organ Act 1994, Rules 1995

10. The Medical Termination of Pregnancy Act 1971

11. Medical Termination of Pregnancy Rules 2003

12. The Mental Health Act 1987

\section{Laws Governing Environmental Safety}

These are the laws aimed at protection of environment through prevention of air, water, surface, noise pollution and punishment of offenders. These laws are listed in Table 5.

Table 5: Laws governing environment safety

1. Air (prevention and control of pollution) Act 1981

2. Biomedical Waste Management Handling Rules 1998 (Amended on 2000)

3. Environment Protection Act and Rule1986, 1996

4. NOC from Pollution Control Board

5. Noise Pollution Control Rule 2000

6. Public Health Bye Law 1959

7. Water (prevention and control of pollution) Act 1974

8. Delhi Municipal Corporation (malaria and other mosquito borne diseases) Bye Law 1975

9. The Cigarettes and Other Tobacco Products (prohibition of advertisement and regulation of trade and commerce, production, supply and distribution) Bill 2003

10. Prohibition of Smoking in Public Places Rules 2008

11. IPC Section 278 (making atmosphere noxious to health), Sec 269 (negligent act likely to spread infection or disease dangerous to life, unlawfully or negligently)

\section{Laws Governing Employment and Management of Manpower}

This group deals with the laws regulating the employment of manpower, their salaries and benefits, service rules and system of redressal of grievances and disputes. These laws are listed in Table 6. 
Table 6: Laws governing to employment and management of manpower

1. Bombay Labor Welfare Fund Act 1953

2. Citizenship Act 1955

3. Delhi Shops and Establishment Act 1954

4. Employee Provident Fund and Miscellaneous Provision Act 1952

5. Employment Exchange (compulsory notification of vacancies) Act 1959

6. Equal Remuneration Act 1976

7. ESI Act 1948

8. ESI Rules 1950

9. Indian Trades Union Act 1926

10. Industrial Dispute Act 1947

11. Maternity Benefits Act 1961

12. Minimum Wages Act 1948

13. Negotiable Instrument Act 1881

14. Payment of Bonus Act 1956

15. Payment of Gratuity Act 1972

16. Payment of Wedges Act 1936

17. Persons with Disabilities Act 1995

18. PPF Act 1968

19. SC and ST ACT 1989

20. Shops and Factories Act (for national holiday)

21. TDS Act

22. The Essential Service Maintenance Act 1981

23. The Payment of Gratuity Act 1972

24. Workmen's Compensation Act 1923

\section{Laws Governing to Medicolegal Aspects}

These are the laws governing the doctor-patient relationship, legal consequences of breach of contract and medicolegal aspects of negligence of duty. These laws are listed in Table 7.

Table 7: Laws governing to medicolegal aspects

1. Consumer Protection Act 1986

2. Indian Evidence Act

3. Law of privileged communication

4. Law of torts

5. IPC Section 52 (good faith), Sec 80 (accident in doing lawful act), Sec 89 (for insane \& children), Sec 90 (consent under fear), Sec 92 (good faith/consent), Sec 93 (communication in good faith).

\section{Laws Governing the Safety of Patients, Public and Staff within the Hospital Premises}

These laws deal with safety of facilities and services against any accidental hazards that may endanger the lives and the liability of management for any violation. These laws are listed in Table 8.
Table 8: Laws governing the safety of patients, public and staff within the hospital premises

1. The Radiation Surveillance Procedures for the Medical Application of Radiation 1989, Radiation Protection Rules 1971

2. AERB Safety Code no. AERB/SC/Med-2(rev-1) 2001

3. Arms Act 1950

4. Boilers Act 1923

5. Explosive Act 1884 (for diesel storage)

6. Gas Cylinder Rules 2004

7. Insecticide Act 1968

8. IPC Section 336 (act endangering life or personal safety of others), Sec 337 (causing hurt by act endangering life or personal safety of others), Sec 338 (causing grievous hurt by act endangering the life and personal safety of others).

9. NOC from chief fire office

10. Periodic fitness certificate for operation of lifts

11. Petroleum Act and Storage Rules 2002

12. Prevention of Food Adulteration Act 1954

13. The Indian Fatal Accidents Act 1955

14. The Tamil Nadu Medicare Service Persons and Medicare Service Institutions (prevention of violence and damage or loss to property) Act 2008

\section{Laws Governing Professional Training and Research}

There are the laws meant to regulate the standards of professional education and training of doctors, nurses, technician and controlling research activities. These laws are listed in Table 9.

Table 9: Laws governing professional training and research

1. $\mathrm{MCl}$ rules for MBBS, $\mathrm{PG}$ and internship training

2. National board of examination rules for DNB training

3. ICMR rules governing medical research

4. $\mathrm{NCl}$ rules for nursing training

5. Ethical Guidelines for Biomedical Research on Human Subjects, 2000

\section{Laws Governing the Business Aspects}

Some rules are applicable to hospital in relation to its business aspects. These are listed in Table 10 .

Table 10: Laws governing the business aspects
1. Cable Television Network Act 1995
2. Charitable and Religious Trusts Act 1920
3. Contracts Act 1982
4. Copyright Act 1982
5. Custom Act 1962
6. FEMA 1999
7. Gift Tax Act 1958
8. Income Tax Act 1961
9. Insurance Act 1938
10. Sales of Good Act 1930 


\section{Licences/Certifications Required for Hospitals}

A hospital administrator should be aware about the licences that are essentially required and to renew them as and when required. These are as listed in Table 11.

Table 11: Licences/certifications required for hospitals

\begin{tabular}{lll}
\hline Sr. no. & Licences/certifications & Frequency \\
\hline 1. & $\begin{array}{l}\text { Registration under societies } \\
\text { registration act }\end{array}$ & Initially \\
& r.
\end{tabular}

2. Inspection for electrical installation/ Initially substation

3. NOC from local municipal office for Initially any bye law

4. Licence for storage of petrol/diesel 2 yearly on form XV under the petroleum rules 2002

5. Income tax exemption certificate

6. NOC from Delhi fire services

3 yearly

Before implementation

7. Registration for operation of X-ray installation with AERB

8. Drug Licence for medical store, IPD pharmacy, OPD pharmacy

9. Licence to operate blood bank under rule $122 \mathrm{G}$ of drug and cosmetic act

10. Registration under PNDT Act 1994

11. Income tax registration/PAN

12. Registration for VAT/Sales tax

13. Registration for EPF

14. Registration for ESI coverage of employee

15. Registration under rule 34 , sub rule (6) of MTP Act 1971

Every 2 years

Every 5 years

Every 5 years

Every 5 years

Once only

Once only

Once only

Once only

One time registration

16.

Registration under Delhi nursing

Yearly Home Act 1953

17. Indemnity insurance policy

Yearly

18. Standard fire and special perils policy

19. Authorization for generation of BMW under BMW handling rule 1996

20. Licence for operating lift under Sect 5 and 6 and Rules 4 and 5 (inspector of lift, state govt)

\section{Periodic Reports and Returns as Legal Commitment}

A hospital administrator should be aware about the reports and returns that are essentially required by different agencies with fixed periodicity. Some of these are listed in Table 12.
Table 12: Periodic reports and return as legal commitment for hospitals

\begin{tabular}{|c|c|c|}
\hline Sr. no. & $\begin{array}{l}\text { Periodic reports and return for } \\
\text { hospitals }\end{array}$ & Frequency \\
\hline 1. & Biomedical waste generation & Annual \\
\hline 2. & Income Tax & Annual return \\
\hline 3. & Units processed in blood bank & Monthly \\
\hline 4. & MTP reports & Monthly \\
\hline 5. & $\begin{array}{l}\text { PNDT report (prenatal USG } \\
\text { done) }\end{array}$ & Monthly \\
\hline 6. & Employees provident fund & Monthly/annual \\
\hline 7. & ESI act & Monthly/annual \\
\hline 8. & VAT & Monthly/quarterly online \\
\hline 9. & Registration of births and deaths & On every occurrence \\
\hline 10. & Post polio paralysis case & On every occurrence \\
\hline 11. & Communicable disease report & On every occurrence \\
\hline 12. & $\begin{array}{l}\text { Radiologist registration under } \\
\text { PNDT }\end{array}$ & $\begin{array}{l}\text { On induction of a new } \\
\text { radiologist }\end{array}$ \\
\hline 13. & $\begin{array}{l}\text { USG machine registration } \\
\text { under PNDT }\end{array}$ & $\begin{array}{l}\text { On induction of each } \\
\text { machine }\end{array}$ \\
\hline 14. & Needle stick injuries & On occurrence \\
\hline 15. & $\begin{array}{l}\text { TLD Badges for monitoring the } \\
\text { dosage received }\end{array}$ & Quarterly \\
\hline 16. & TDS & Quarterly \\
\hline
\end{tabular}

\section{CONCLUSION}

The health legislations are very few as compared to the size and problems in the health care sector. There is a need for having a comprehensive health care act, framed in order to gear the entire health care sector to the objectives laid down in the different policy in India. Most of the common medico legal situations arise out on noncompliance with these rules and regulations. If a hospital or doctor acquaints well with these rules and regulations and follows them sincerely, he/ she would be on the right side of the law.

\section{REFERENCES}

1. Sinha TK, Times of India. Mumbai edn, Jun 12, 2012. p. 5.

2. Henry SE, A history of medicine, Vol II, Early Greek, Hindu and Persian medicine, Oxford University Press, 1987;(2). p. 142-143.

3. Rangarajan LN, Kautilya's Arthashastra, New Delhi, Penguin Books, 1st ed. p130-131.

4. Kosambi DD. The culture and civilisation of ancient India in historical outline, New Delhi, Vikas Publication 1970:160.

5. Chattopadhyay D. Science and society in ancient India. Research India Publication, 1979 edn. p-22.

6. Ramasubban R, Public health and medical research in India: their origins lender the impact of British Colonial Policy' SAREC. 1982;R.4

7. Singh J, et al. Medical Negligence and Compensation. Bharat Law Publication, 3rd edition. p.2-4.

8. Joshi SK. Quality Management in Hospitals. Jaypee Brothers Medical Publishers, 1st edition. p 368-369. 